\title{
Professional and Organisational Commitment in the Hospitality Sector
}

\author{
Marjetka Rangus \\ University of Maribor, \\ Faculty of Tourism, Slovenia \\ marjetka.rangus@um.si \\ Srđan Milošević \\ Educons University, \\ Faculty of Sport and Tourism, Serbia \\ srdjan.milosevic@tims.edu.rs \\ Iva Škrbić \\ Educons University, \\ Faculty of Sport and Tourism, Serbia \\ iva.skrbic@tims.edu.rs
}

\author{
Bojana Radenković-Šošić \\ Educons University, \\ Faculty of Sport and Tourism, Serbia \\ radenkovicbojana@gmail.com \\ Jože Hočevar \\ Terme Čatež d.d, Slovenia \\ joze.hocevar@terme-catez.si \\ Mladen Knežević \\ Libertas International University, \\ Faculty for International Relations \\ and Diplomacy, Croatia \\ mknezevic@libertas.hr
}

The purpose of the study is to examine whether two different work commitment profiles influence service quality in the hospitality sector in Slovenia and Serbia and how the implications of the differences can be used in the tourism and hospitality industry. Combining a qualitative and quantitative approach, two new instruments were developed for this study. The first instrument was created on the basis of short, structured interviews with employees. Two factors explaining the two different commitment profiles were determined with statistical analysis and with the method of clustering, four dimensions of commitment profiles forming were extracted. The second instrument was developed on the basis of existing evaluation forms for employees in the tourism industry and interviews with leading and middle managers of hotels. The findings of the study show that there is a small proportion of professionallyoriented employees in the tourism sector, and the difference among employees is evident in the ranking of working values. These results could be useful for managers in planning and organising their human resources and also in planning further development of their companies' human resource policies. The original contribution of the article is the ranking of working values and the perception of quality work by employees in the hospitality sector. The study also reveals new evidence on different types of commitment profiles.

Keywords: tourism, hospitality, organisational commitment, professional commitment, human resources management

(cc) BY-SA https://doi.org/10.26493/2335-4194.13.179-191

\section{Introduction}

There is a widely-accepted opinion in academic and professional circles that the tourism and hospitality sector does not provide an optimum environment for successful career building and professional growth. Research in the field of hospitality offers different ex- 
planations for this phenomenon. The tourism and hospitality industry records high employee turnover rates (Iverson \& Deery, 1997; Hjalager \& Andersen, 2001; Baum \& Thompson, 2007; Hussey et al., 2010; Karatepe \& Shahriari, 2014; Kim, 2014), such that turnover is often acceptable and is understood to be the norm (Iverson \& Deery, 1997). One reason for the lack of good, stable careers in the sector is that tourism and hospitality jobs involve long working hours, especially during weekends and holidays, sometimes extreme working and weather conditions, stress and demands, as well as special attitudinal norms, which are in the domain of personal character traits rather than skills and knowledge (see Hussey et al., 2010; Hussey et al., 2011; Mackenzie \& Kerr, 2013; Lee, 2014). Employment in the hospitality industry is expected to grow more slowly in the coming years (Baum, 2015; Dogru et al., 2019).

Research (Ap \& Wong, 2001; Brown et al., 2011; Kim, 2014) shows that good working conditions and career opportunities are crucial for building stable employment and the development of professionalism. Employees respond to high levels of organisational support with high levels of organisational commitment and psychological attachment, obligation, and loyalty (Brougham \& Haar, 2018). These also play a part in the execution of excellent tourism service, resulting in keeping customer loyalty. Also, organisational culture and values are an important part of career development perceptions and employee structure, since they attract people with similar values, beliefs, knowledge, skills and abilities (Gorenak \& Ferjan, 2015). Human potential is increasingly recognized as an essential asset for organisations (Silva \& Martins, 2016). However, Hjalager and Andersen (2001) suggest that, because of the high fluctuation of workers in the industry, low-skilled jobs and low rates of relevant tourism education among tourism employees, the tourism sector is a border market for human resources that shares a pool of possible employees with many other sectors that offer better salaries and career opportunities. According to Hjalager and Andersen (2001), tourism jobs tend to be temporary solutions for new employees in the workforce or in times of economic crisis, which together with the often sea- sonal nature of the jobs explains the high turnover rate in the sector. It is important to point out that high turnover rates and lack of professionalism are not only confined to developing countries or countries in transition (Baum, 2007).

Previous research in the field also shows that employees who have had professional tourism education tend to change jobs less frequently than those who have not or have different qualifications (Hjalager \& Anderson, 2001). Moreover, people with previous job experience in the sector tend to develop a more professional attitude towards their jobs (Kim, 2014).

Employees with elevated levels of turnover intentions have low morale, deliver poor service and erode service recovery efforts, which in the end have an impact on guests and can result in bad reviews, complaints and finally loss of guests (Ap \& Wong, 2001; Karatepe \& Shahriari, 2014). Satisfied, stimulated and professional employees in the service sector are thus crucial to all service industries and should be a main concern of hospitality management (Brown et al., 2011; Ineson et al., 2013; Karatepe \& Shahriari, 2014).

To assure high quality of service, tourism companies should be aware of the importance of human resources management and should strive for optimal employee profiles in the business. In order to determine what type of work commitment profiles predict quality of service, we set up two hypotheses:

H1 Employees who have high professional commitment will perform their tasks better.

$\mathrm{H} 2$ Employees who have high professional commitment are more likely to have had a proper education relevant to the job they are doing.

\section{Theory}

Research in the field suggests that employees have different types or profiles of work commitment. The latest research on employee commitment profiles shows that commitment profiles have substantial temporal stability and do not change easily over time (Kam et al., 2016). Research indicates that different forms of work commitment are connected to job involvement and quality of service (Gouldner, 1957; 1958; Carson et al., 1999; Cohen, 1999; Sinclair et al., 2005; Kam et al., 
2016). In his pioneer study on different types of loyalty, Gouldner established that over the years employees in an organisation develop different types of loyalty or commitment to their work (Gouldner, 1957; 1958). Gouldner's research suggests that employees have two types of loyalty orientation. The first group of employees (locals) tend to be more committed to organisations they work in and their local subgroup in the organisation. They are high on loyalty to the employing organisation and low on commitment to specialized skills (Gouldner, 1957). The second group (cosmopolitans) of employees tend to be high on commitment to specialized role skills, low on loyalty to employing organisations and likely to use an outer reference group orientation (Gouldner, 1957), thus they are more likely to be mobile and pursue their careers in other organisations.

Later research on work commitment has resulted in different models of commitment forms (see Randal \& Cote, 1991; Meyer \& Allen, 1997; Carson et al., 1999). In accordance with Gouldner, four committed (Carson et al., 1999) profiles of workers have been identified, thus answering Gouldner's dilemma of whether both types of loyalty can be recognised in one person (Carson et al., 1999). Morrow (1993), in her research, determines five universal forms of work commitment, which are relevant to many employees. These foci of work commitment are affective commitment to organisation, continuance commitment to organisation, career commitment, work ethic and job involvement (see Cohen, 1999). Morrow's study suggests the possible interrelationships among the five commitment forms. Cohen's (1999) research on Morrows' theory has determined that it is only a presumption that each of the five forms is an independent construct. Cohen's research further shows that job involvement seems to be the key mediating variable in the interrelationships among work commitment constructs (Cohen, 1999).

In other scholarly literature on work commitment, professionalism is defined as the predominance of career commitment in an employee's commitment profile compared to other work commitment profiles (e.g. Blau, 1985; Ellemers et al., 1998; Cohen, 1999). In typologies where professional commitment is not defined (e.g. Gouldner, 1957; 1958; Randall \& Cote, 1991;
Carson et al., 1999), terms like 'career commitment,' 'professional commitment' and 'occupational commitment' are used to explain commitment to vocation, career or profession. Morrow (see Cohen, 1999) connected career commitment to the Protestant work ethic, suggesting that this is the most stable commitment form, because it is learned through the socialisation process and is less related to characteristics of the work setting (Morrow, 1993, in Cohen, 1999) where one is more narrowly focused on one's own career or vocation. In other research, career commitment is connected to high job withdrawal cognitions, feelings of self-efficacy, ongoing training and continuing education (Carson et al., 1999). Although the definitions have some commonalities and are sometimes used in all contexts, they should not be interchanged. According to Blau (1985), career commitment can be defined as one's attitude towards one's profession or vocation, whereas professional commitment can be operationalised in terms of the individual's reluctance to leave his/her professional role (Thornton in Blau, 1985), i.e. commitment to his/her vocation or profession. In theory, professionalism and professional commitment is related to outer reference groups, i.e. professional associations (Gouldner, 1957; 1958), reading journals, attending meetings and joining associations (Price \& Mueller, 1981). In the tourism sector, professionalism is based on many dimensions, not all of which can be learned or trained. Hussey et al. (2011) argue that professionalism in tourism can be conceptualised by the following ten dimensions: profession as a referent group, altruism, belief in self-regulation, sense of calling, autonomy, body of knowledge, concern for service quality, code of ethics, special skills and expertise, and professional identity.

Organisational commitment refers to the predominance of one's attachment to the organisation in one's work commitment profile (Ellemers et al., 1998, pp. 717-718). Affective organisational commitment is related to employees' emotional attachment to an organisation, the match of personal values and the values of the organisation and identification with the company (Ellemers et al., 1998; Cohen, 1999; Sinclair et al., 2005; Kam et al., 2016). Continuance commitment, on the other hand, is defined as the perception that the 
cost of leaving exceeds the cost of remaining (Ellemers et al., 1998; Cohen, 1999; Sinclair et al., 2005; Kam et al., 2016). Organisational commitment has a significant direct influence on job performance (Youn et al., 2018). According to Dhar (2015) organisational commitment strongly influences the quality of guest services. Perceived organisational support, such as the value of contributions and caring about the well-being of the employee, significantly affects organisational commitment (Kim et al., 2016).

For the purpose of our research, we needed to develop a new kind of instrument that would differentiate the two types of work commitment profiles of employees in tourism as extreme poles in work commitment profile categorisations. This distinction was first set up by Gouldner (1957). Later, Ellemers et al. (1998) polarised career oriented-commitment to team-oriented commitment, of which the latter proved to be closely related to organisational commitment. Their research has shown that organisational commitment is stronger among respondents with longer job tenure and greater work satisfaction (Ellemers et al., 1998). They have also shown that employees who are more career oriented are less likely to help their team colleagues at the expense of their own work and that those committed to the organisation are more likely to work overtime (Ellemers et al., 1998). Another very important finding from their research is that a certain type of work commitment profile does not predict task performance ratings (Ellemers et al., 1998).

This study set out to analyse whether there is a difference in the quality of work (performance) between two groups of employees (those who are more committed to the organisation and those who are more committed to the profession).

\section{Materials and Methods}

In order to realise the objectives of our research, we used two instruments. In spite of all the provided definitions, we decided to take an emic approach to this research and to establish definitions which would be understandable and unified to employees participating in the research. The first instrument was created to assess whether an individual is more committed to an organisation in which he or she is employed or to his/her profession. We assumed that employees would either be typically committed to their organisation (both affective and continuance) or to professionalism. The second instrument was developed to evaluate the quality of work of employees who participated in the project.

To establish the two commitment profiles, a new instrument was designed especially for this project. To make the instrument as comprehensible as possible, we made certain that the use of words and definitions were from the employees' points of view. Accordingly, definitions of the two commitment profiles as explained by the participating employees were used.

In the first stage of creating the instrument, we employed a qualitative methodology. Researchers in the field were students from the Faculty of Tourism of the University of Maribor, Slovenia, and young associates and teaching assistants from the Faculty of Sport and Tourism in Novi Sad, Serbia. In this way, we assured the results from culturally diverse backgrounds in order to avoid local determination of the results. All interviewers, before conducting fieldwork, were educated in techniques of conducting interviews and how to take notes from the interviews - they were informed that they had to take completely verbatim notes. Each group was supervised in the field by one of the researchers. No one needed the intervention of the researchers.

The interviewers visited various hospitality organisations and asked employees to answer two structured questions: (1) What are the characteristics of someone who is committed to her/his profession? and (2) What are the characteristics of someone who is committed to the organisation in which she/he is employed? Researchers worked in pairs, with one asking questions and the other recording the answers verbatim. We did not want to record conversations for reasons of confidentiality between the interviewers and the employees. We were aware that some employees might consider the questions and their responses to be threatening to both their relationships with their superiors and their careers. To minimise any kind of influence or the interviewees' discomfort with the process, we asked students to do the interviews. Interviews were 
Table 1 Dimensions of Indexes Explaining the Factors

\begin{tabular}{ll}
\hline Commitment to organisation & Commitment to professionalism \\
\hline Attitude towards respecting the house rules & Attitude towards guests \\
Attitude towards co-workers & Attitude towards knowledge \\
\hline
\end{tabular}

conducted with a total of 60 employees. Researchers recorded a total of 314 responses to our questions.

Next, a panel of researchers was organised where researchers from the universities, as well as practitioners, professionals employed in the hospitality and hotel industry, were engaged. Out of the total collected statements, we first isolated the ones that were repetitions. In the next step, statements that did not meet the purposes of the research were isolated. The remaining total of 103 claims was prepared for further processing. Of this number, there were 45 statements related to commitment to the profession and 58 to commitment to the organisation in which the interviewees were employed. The statements were formulated in sentences and an instrument with a 5-point Likert scale was created. The sentences were formulated in the first person: 'I am aware of the importance of team-work.'

To create the final form of the questionnaire, we offered the instrument to students of various faculties at the University of Maribor (Slovenia), Libertas Business School of Zagreb (Croatia) and the University Educons in Novi Sad (Serbia). The research included a total of 867 male and female students. All students participated voluntarily. The research was conducted in groups of up to 50 students. Before each group of students filled in the questionnaires, a researcher from the team gave instructions on how to use the instrument and each student filled out a questionnaire individually.

In the first step of the instrument design, we made a correlation analysis of all statements in the questionnaire. We decided to exclude all claims that did not reach the value of Pearson's correlation coefficient of o.50. In this way, we excluded another 64 statements from further procedures. The remaining 39 statements were analysed using principal components analysis. Four principal components explained 57.35 per cent of the variance. Following that, we excluded from further analysis another seven statements that had not achieved more than 0.50 communality. Thus, all the components explained 59.67 per cent of the variance. The remaining 32 were deployed into two predicting factors (commitment to the profession and commitment to the organisation).

To achieve the highest internal consistency, each individual factor was adjusted until we achieved a satisfactory value for Cronbach's alpha coefficient. For the scale 'commitment to the profession,' Cronbach's alpha coefficient was 0.878 . The scale consisted of nine statements. The scale of 'commitment to the organisation' also contained nine statements and Cronbach's alpha was 0.904. These internal consistencies are satisfactory for an instrument of this kind (Table 1). Thus, through our research, the two types of commitment were determined by two clusters of indexes. The commitment to the organisation profile was explained by dimensions of 'attitude towards house rules' and 'attitude towards co-workers', while the commitment to professionalism profile was explained by the dimensions of 'attitude towards guest' and 'attitude towards knowledge.'

To assess the quality of employees' performance, we used an improved instrument, routinely used for this purpose, in one of the largest Slovenian hotel companies. Standard instruments for assessing the quality of service were not included, since they only assess the service from the guests' points of view and do not give any information on employees' attitudes in an organisation or they are too complex to be used in such a study. The basic instrument was supplemented with the criteria suggested by the groups of managers in various tourist organisations. The instrument evaluated the following categories on a Likert scale from 1 to 5 (Table 2).

The final instrument for employees consisted of 18 statements and some demographic questions. The statements were put in random order to minimise the influence of previous statements on the rating of the 
Table 2 Categories Evaluated by the Managers

1 Communication
2 The ability to participate in a team
3 Respect for colleagues
4 Ingenuity, continuous search for solutions
5 Ability to innovate
6 Compliance with superiors
7 Organisational skills
8 Self-initiative
9 The ability to transfer problems to their superiors -
are able to propose solutions
10 Flexibility
11 Loyalty to the company, identify with the vision of the
company
12 Tidiness and accuracy
13 Knowledge of complete range of businesses offered
14 Professionalism on the job
15 Care for the guests (kindness, knowledge of service,
potential appeals to service

participants' next statements. The instrument was offered to 249 employees in hotels in Serbia and Slovenia. Of all, 66 of them refused to participate. It was explained to employees that the survey could not be anonymous, because their performance in the workplace would be assessed by their direct superiors. In order to be able to connect both types of data, the employees had to agree to put their names on the questionnaires. Employees were assured that the results of their answers would not be available to their managers. Once employees agreed on the method of the research and responded to the questionnaires, the names of the participating employees were submitted to their managers. Managers were asked to rate each employee according to the scale presented above. Managers were presented with special evaluation forms for each employee.

\section{Results and Discussion}

The vast majority of our respondents were female, which approximates the situation in the tourism sector in Slovenia and Serbia. This industry is dominated by the female population. In our sample, there were
Table 3 Employees' Education

\begin{tabular}{lrr}
\hline Type of education & $f$ & $\%$ \\
\hline Unknown & 14 & 7.7 \\
High school & 106 & 57.9 \\
College education & 22 & 12.0 \\
University or equal professional education & 35 & 19.1 \\
Master of Science or higher & 6 & 3.3 \\
\hline Total & 183 & 100.0 \\
\hline
\end{tabular}

slightly more women than men, but this fact did not affect the general statistical impression.

Most employees had secondary education (Table 3). The number of employees with college or university education was relatively high. This result differs from the educational structure that is typical for this sector, which has been shown to have a relatively lower educational level. As stated, in our sample, the proportion of employees with higher levels of education was unexpectedly high. There are probably two explanations for this situation. First, in the participating countries, in the past 10 years, there has been a great stimulation of education by the government, especially of higher education. This expansion has occurred in both the private and public education sectors. The second reason could be attributed to the period of economic crisis, which is why many highly educated people work in jobs that are far below their educational qualifications. This is particularly evident in the fact that 66 per cent of employees with secondary education and 44 per cent of employees with higher levels of education do not work in the professions they are educated for. Exceptions are employees with college education who work mostly as managers. Only 27.3 per cent of them work in jobs that they are not educated for.

In our study, 54.6 per cent of the respondents were currently working in jobs for which they were not properly educated. In the Slovenian and Serbian education system, the field of hospitality is inflexible and students are educated in only a few very traditional occupations. There is little variability and therefore students are not trained to adapt to business conditions that are dynamically changing. On the other hand, the hospitality industry has never set standards and 
demands for specific forms of education in the sector, which leaves the question of professionalism in tourism open. Closely related to this argument is the case of the private sector and small tourism businesses that avoid hiring educated employees because, according to state work legislation, employers should provide them with better salaries.

The average age of the participants, 37.65 years, indicated a relatively low level of employment dynamics. The average number of companies where they were employed was 2.48 , which is another proof of the relative immobility of the workforce in the sector. The youngest participant in our research was 19 years old and the oldest 62 years. Almost 76 per cent of the employees had worked for 3 or even fewer organisations, which indicates low turnover rates. This fact, not commonly referred to in the tourism sector, can be attributed to a specific working culture and ethic stimulated by the previous socialist regime. Kalleberg and Stark's (1993) research shows that employees in socialist economies are not primarily concerned with their careers, compared to their us colleagues. Vodopivec (2014), in her interviews with workers and directors of a textile company in the socialist regime in Slovenia, reports on the importance and intentional building of company loyalty and solidarity among co-workers.

Low labour mobility has proved to be related to traditionalism in family relationships. Thus, in our study, among employees who had 5 years' working experience, 71 per cent of those were not married and stated their marital status as 'single.' In the group where employees had 5-10 years of experience, the number of unmarried employees was 31 per cent and the number of employees who were married was 59 per cent. Changes of employment in small communities with these conditions can be highly complicated and risky, because there are many factors that are sometimes impossible to reconcile with each other. Small communities offer very limited employment opportunities, as there are only a small number of companies and therefore low dynamics of the workforce. For example, unfavourable working hours and childcare is a particularly important factor. However, what is probably an equally important contributor to relatively low labour mobility is the conviction of almost 60 per cent of our respondents that they had the possibility of advancing in their companies. This idea was rejected by the remaining nearly 40 per cent of respondents (38.8 per cent). In contrast to this view, almost half of the respondents (46 per cent) claimed that they were thinking about leaving their companies. The share of those respondents with families was fully equal to those who were single or divorced. When it came to thinking about leaving their current companies, there were an equal proportion of those who were employed for an indefinite period and those who were employed for a limited time.

Results of the assessment of the level of commitment to the profession and commitment to the organisation were more than surprising. In many studies of the labour force in this profession, it has been pointed out that people working in the tourism sector are those who prefer social contact and who therefore tend to be more professionally oriented. In our study, only 17 respondents or 9.3 per cent were somewhat to a greater extent committed to their profession than to the organisation in which they were employed. Thus, asymmetric data makes further statistical analysis more or less meaningless.

Nearly 60 per cent had completed high school, which was completely in line with the educational structure of the respondents in the sample. Most of them were in the between 29 and 36 years age group. In this age group, we found that 41 per cent of those were more committed to their professions than the organisations. So this was a group with solid life experience, and also solid work experience, who obviously had a strong desire to advance in their professional development. Among them, there were an equal number who had families and those who did not yet have them, which is surprising to some extent.

Although the theory states that commitment to profession has different roots, it also suggests that employees with higher levels of professional orientation will place a primacy on work in their lives (Blau, 1985). This is also related to the belief that individuals can influence or control their careers. More than half of them said that their companies did not provide for systematic additional professional education. Again, awareness of the importance of life-long learning ex- 
periences and additional professional qualifications is expected from those employees who rank higher on professional commitment, since they are looking for something more than just a job. Almost 60 per cent of them had already considered leaving their companies and wanted to find a good grounding for their professional ambitions elsewhere, which is also in line with previous research in the field, suggesting that withdrawal cognition predicts career or professional commitment (Price \& Mueller, 1981; Blau, 1985; Ellemers et al., 1998; Carson et al., 1999).

Results of the research confirmed some previous hypotheses on work commitment profiles. When polarising work commitment types, according to Gouldner's division, only 9.3 percent of employees could be defined as clearly high on professional commitment and more than 90 percent were high on organisational commitment. Since we did not analyse all other types, namely dually committed and uncommitted, we can only assume that there was also a large proportion of those among those interviewed. Results also suggest that there were only a handful of those who were really dedicated to their professions in the hospitality sector, which perhaps has alarming implications for quality of service in Slovenia and Serbia.

Along with the studies of Price and Mueller (1981), Blau (1985), Ellemers et al. (1998) and Carson et al. (1999), we found that in the tourism sector organisational commitment is related to job tenure and age. But, surprisingly, the tourism sector in Slovenia and Serbia does not report high turnover rates, as seems to be the case all over the world, since the participants in the research worked in fewer than 3 companies on average and many of them had worked in the same company all their work life. Nearly 20 per cent of respondents (18.8 per cent) had remained with their original companies.

When the participants were divided into groups according to the quintiles, the majority of those who had never changed companies were from the oldest group of respondents. 84 per cent of the members of the oldest group had changed a maximum of 2 companies or had not changed companies at all. This again indicates very low labour mobility in this sector. Here, it is worth mentioning that in the group of those who appeared to be somewhat more committed to their professions than to the companies, there was almost no one who had not changed companies (only 1 person). Members of all age groups were equally prone to move from one company to another. This tendency changes a little bit more intensively in the second quartile with those members of the group who had an average of between 8 and 15 years of work experience. Although on the basis of our results we cannot make generalisations, it seems that mobility is statistically slightly higher with those who were more committed to their professions than to the organisations in which they work. This is again in accordance with previous findings, because commitment to a profession also means seeking the best possible conditions for professional development.

As previously mentioned, this can be explained by the specific historical influence of the socialism regime ideology, as ethics lie in organisational loyalty and community solidarity and not in the endeavour for individual and successful careers.

Research also shows the need for a more structural and strategic approach to the system of formal education for tourism professions, as already pointed out by Hussey et al. (2011). In spite of high overall levels of education, there is still an evident lack of proper education for tourism vocations at all levels. According to our findings, more than half of employees also reported that tourism companies themselves do not provide for additional training, i.e. they do not express very much interest in additional training for their employees and are not yet aware of the importance of professional knowledge and skills for their front-line employees.

Data on individual performance ranking bring some other interesting evidence to consider. Due to the extreme asymmetry of distribution, there is no justification for the statistical comparison of the two groups. But if the item from the structured questionnaire is treated as the value associated with the work, it makes sense to analyse the hierarchy of these values. Average values and their standard deviations are shown in Table 4.

Both groups of employees, those who were committed to their companies and those who were com- 
Table 4 Comparison among the ranks of Some Items

\begin{tabular}{|c|c|c|c|c|c|c|}
\hline \multirow[t]{2}{*}{ Item } & \multicolumn{3}{|c|}{ Organisation } & \multicolumn{3}{|c|}{ Profession } \\
\hline & (1) & $(2)$ & (3) & (1) & (2) & (3) \\
\hline I do my work fairly. & 1. & 4.86 & 0.531 & 1. & 4.65 & 0.996 \\
\hline I try to be friendly and kind to the guests. & 2. & 4.86 & 0.531 & 2. & 4.59 & 1.004 \\
\hline I am aware of the importance of good team work. & 3 . & 4.81 & 0.454 & 8. & $4 \cdot 35$ & 1.057 \\
\hline I try to be good at my work. & 4. & 4.78 & 0.555 & 13. & 4.24 & 1.091 \\
\hline The company can rely on me. & 5 . & 4.76 & 0.626 & 11. & 4.24 & 1.033 \\
\hline I try to do my work with utmost quality. & 6. & 4.69 & 0.548 & 16. & 4.00 & 1.000 \\
\hline At work, I try to be in a good mood. & 7. & 4.68 & 0.705 & 3 . & 4.59 & 0.795 \\
\hline I am always neat at work. & 8. & 4.67 & 0.616 & 10. & 4.24 & 1.033 \\
\hline My attitude is the same in the pres. of sup. and when they are not around. & 9. & 4.67 & 0.655 & 15 & 4.06 & 1.088 \\
\hline I believe I know how to serve a guest. & 10. & 4.63 & 0.654 & 7 . & 4.41 & 1.064 \\
\hline I respect the instructions of superiors. & 11. & 4.63 & 0.724 & 18. & 3.88 & 1.054 \\
\hline I have good relations with my colleagues. & 12. & 4.57 & 0.673 & 17 & 3.88 & 1.054 \\
\hline I strive for improvements of work organisation and work processes. & 13. & 4.45 & 0.702 & 9. & 4.29 & 1.047 \\
\hline I work in my profession with enthusiasm. & 14. & $4 \cdot 37$ & 0.876 & 14. & 4.18 & 0.883 \\
\hline I enjoy my work. & 15 & 4.11 & 1.000 & 5 . & 4.47 & 1.007 \\
\hline I constantly train for my profession. & 16. & 4.07 & 1.075 & 4 . & 4.47 & 1.007 \\
\hline I invest in my knowledge in my free time. & 17. & 3.86 & 1.057 & 6. & 4.41 & 1.064 \\
\hline I work together with students on their res. papers and practical education. & 18. & 3.73 & 1.261 & 12. & 4.24 & 1.147 \\
\hline
\end{tabular}

Notes Column headings are as follows: (1) rank, (2) mean, (3) standard deviation.

mitted to their professions, put the same two values on the first two places. These are the values of fairness at work and kind and friendly attitudes towards guests, which in a way are universal values in the hospitality industry. In general, we can say that those groups who were more committed to their companies ranked higher in values associated with respect for the rules of the company, while the groups of dedicated professionals highlighted individual values showing enjoyment of the work being performed and education for the job. Thus, for example, the item 'I enjoy my work' was ranked in 15 th place by those who were dedicated to their organisations, but 5 th by those who were dedicated to their professions. It is important to note that constant training for the job was essentially assessed differently by the two groups. Those who were more committed to their profession put far more value on education than those who were committed to the or- ganisation. The organisation clearly represents a collective identity in which it is necessary to respect the rules of the collective.

Occupation, on the other hand, represents a personal relationship to work, and the constant improvement of knowledge and skills reflects the relationship towards oneself and one's profession. As a result, the latter group may neglect teamwork, ignoring the importance of collective rules. For them, the general rules of the profession are more important than the particular rules of their company. Those who are more committed to the profession assign less importance to the instructions of superiors, but at the same time behave the same whether superiors are present or not. It is a good reflection of their relationship to the profession in which they work.

If we list the items according to the four dimensions presented in Table 1, we see another interesting distri- 
Table 5 List of Dimensions of the Items Rated by Employees

\begin{tabular}{|c|c|c|}
\hline & Commitment to the organisation & Commitment to the profession \\
\hline 1 & Attitude towards respecting the house rules & Attitude towards respecting the house rules \\
\hline 2 & Attitude towards guests & Attitude towards guests \\
\hline 3 & Attitude towards co-workers & Attitude towards guests \\
\hline 4 & Attitude towards respecting the house rules & Attitude towards knowledge \\
\hline 5 & Attitude towards respecting the house rules & Attitude towards knowledge \\
\hline 6 & Attitude towards respecting the house rules & Attitude towards knowledge \\
\hline 7 & Attitude towards guests & Attitude towards guests \\
\hline 8 & Attitude towards respecting the house rules & Attitude towards co-workers \\
\hline 9 & Attitude towards co-workers & Attitude towards knowledge \\
\hline 10 & Attitude towards guests & Attitude towards respecting the house rules \\
\hline 11 & Attitude towards respecting the house rules & Attitude towards respecting the house rules \\
\hline 12 & Attitude towards co-workers & Attitude towards knowledge \\
\hline 13 & Attitude towards knowledge & Attitude towards respecting the house rules \\
\hline 14 & Attitude towards knowledge & Attitude towards knowledge \\
\hline 15 & Attitude towards knowledge & Attitude towards co-workers \\
\hline 16 & Attitude towards knowledge & Attitude towards respecting the house rules \\
\hline 17 & Attitude towards knowledge & Attitude towards co-workers \\
\hline 18 & Attitude towards knowledge & Attitude towards respecting the house rules \\
\hline
\end{tabular}

bution of values connected to the work. In the group of employees who tend to be more committed to the organisation, all the items connected to attitudes towards knowledge are put in the last 6 places (see Table 5). In the first half of the values, only two, those connected to attitudes towards guests, can be found. Similarly, concerning the first half of the items of employees who tend to be more committed to the profession, only two items connected with attitudes towards respecting the house rules and co-workers are found. Also, it is evident that employees who tend to be more committed to the profession rate the values connected to knowledge and guests higher than the other group. They also put all three items, which express attitudes towards guests, in the first half of the values. Again, it is important to stress that both groups rate the same items as the majority and consider them to be of the same importance. Of the two, one is connected to attitudes towards respecting house rules and the other with attitudes towards guests.

\section{Testing the Hypotheses}

Our first hypothesis, that employees who are higher on professional commitment will get better performance ratings, must also be rejected. As indicated by Ellemers et al. (1998), our research shows no relationship to any type of work commitment. Thus, we can say that the type of work commitment does not predict performance ratings. There were few differences between the two types of commitment, according to specific dimensions of the measure.

The only difference between the two types of work commitment was seen in the category of innovativeness, where employees with higher levels of professional commitment were rated statistically better than the others. This result seems logical but is again surprisingly different from Ellemers et al's research where they report that contextual performance, which they understand to be initiative or enthusiasm, is related to the dimension of commitment to teams of co-workers (Ellemers et al., 1998). The latter has been exposed as 
a dimension of commitment to organisation in our study.

Related to our second hypothesis on relationship between the type of commitment and proper education for tourism we can hardly draw any conclusion because the distribution of data is asymmetrical. It is interesting that of those who were more committed to the profession, 13 of them are women. As many as 16 of them had more than 5 years of experience, so these were people who had good insights into the profession. About half of them were educated in a profession in which they work, which made them virtually indistinguishable from the majority of respondents. According to this result, we can reject our hypothesis that employees who are higher on professional commitment are more likely to have the proper education for the job in which they work.

\section{Conclusion}

Research on different forms of work commitment profiles shows that characteristics of profiles are not uniform all over the world. The study demonstrates that cultural and societal dimensions on the micro level of the globalised hospitality sector influence work commitment profiles, which, as in the case of Slovenia and Serbia, may differ from work commitment profiles in other parts of the world. The study also points out the relatively modest number of those employees in the hospitality sector who are more committed to their professions than to the organisations. However, the only statistically proven difference between the two profiles in this research is the category of innovativeness, so we can say that employees who rank highly on professional commitment are slightly more innovative than those who are more committed to the organisation. Research also shows that instruments and criteria usually used for assessing the quality of work of employees do not necessarily apply to all professionally oriented employees. Further development of assessment criteria is needed.

Another point that is evident from the results of the research is the fact that professionals in the hospitality sector differ to some extent from professionals in other fields in that they have the same educational background as those employees who are more committed to their organisations. Furthermore, there is also the same proportion of those who have families in both groups of employees.

The most interesting information on the two types of commitment profiles is the ranks of values connected to the work. Those employees who are more professionally oriented ranked the items on the list more carefully and there is a smaller difference between the highest and the lowest rank of items than in the group of more organisationally-oriented employees. The least important work values for this group proved to be respecting instructions and having good relationships with colleagues, while items connected with high quality of work (being in a good mood and constant training in the profession) were ranked 3 rd and 4th place. These results could be useful for managers in planning and organising their human resources and also in planning further development of their companies' human resource policies. On the basis of the results of the research, we can assume that the type of work commitment profile that is more dedicated to an organisation is better suited for big organisations or hotel resorts where respect for rules and strict organisation is necessary for providing high levels of service. On the other hand, we can assume that employees who are more professionally oriented can better perform in working environments where they can express their creativity and where deviation from specific arrangements is even desirable. The instrument for assessing the individual level of work commitment profile could be used in the process of a cadre selection, helping managers find optimal work positions for their employees and vice versa.

The research, however, leaves room for further study on differences between the profiles and the characteristics of both profiles. Also, there is another field open for research, namely assessing the quality of work performance. The instrument used in this study proved to be inadequate for measuring all the categories of work quality and thus more research needs to be done in order to develop new measures.

\section{References}

Ap, J., \& Wong, K. K. F. (2001). Case study on tour guiding. Tourism Management, 22(5), 551-563. 
Baum, T, (2007). Human resources in tourism: Still waiting for change. Tourism Management, 28(6), 1383-1399.

Baum, T. (2015). Human resources in tourism: Still waiting for change? A 2015 reprise. Tourism Management, 50(6), 204-212.

Baum, T., \& Thompson, K. (2007). Skills and labour markets in transition: A tourism skills inventory of Kyrgyzstan, Mongolia and Uzbekistan. Asia Pacific Journal of Human Resources, 45(2), 235-255.

Blau, G. J. (1985). The measurement and prediction of career commitment. Journal of Occupational Psychology, 58(4), 277-288.

Brougham, D., \& Haar, J. (2018). Smart technology, artificial intelligence, robotics, and Algorithms (s T A R A). Journal of Management \& Organization, 24(2), 239-257.

Brown, S., McHardy, J., McNabb, R., \& Taylor, K. (2011). Workplace performance, worker commitment, and loyalty. Journal of Economics and Management Strategy, 20(3), 925-955.

Carson, K. D., Carson, P. P., Roe, C. W., Birkenmaier, B. J., \& Phillips, J. S. (1999). Four commitment profiles and their relationships to empowerment, service recovery, and work attitudes. Public Personnel Management, 28(1), $1-13$.

Cohen, A. (1999). Relationship among five forms of commitment: An empirical assessment. Journal of Organizational Behaviour, 2o(3), 285-308.

Dhar, R. L. (2015). Service quality and the training of employees: The mediating role of organizational commitment. Tourism Management, 46, 419-430.

Dogru, T., McGinley, S., Line, N., \& Szende, P. (2019). Employee earnings growth in the leisure and hospitality industry. Tourism Management, 74, 1-11.

Ellemers, N., de Gilder, D., and van den Heuvel, H. (1998). Career-oriented versus team-oriented commitment and behaviour at work. Journal of Applied Psychology, 83(5), 717-713.

Gorenak, M., \& Ferjan, M. (2015). The influence of organizational values on competencies of managers. Business Administration and Management, 18(1), 67-83.

Gouldner, A. W. (1957). Cosmopolitans and locals: Toward an analysis of latent social roles 1. Administrative Science Quarterly, 2(3), 281-306.

Gouldner, A. W. (1958). Cosmopolitans and locals: Toward and analysis of latent social roles 2. Administrative Science Quarterly, 2(4), 444-480.

Hjalager, A-M., \& Andersen, S. (2001). Tourism employment: Contingent work or professional career? Employee Relations, 23(2), 115-129.
Hussey, J., Holden, M. T., \& Lynch, P. (2010, 15-17 June). Defining professionalism in the tourism context. Paper presented at the Tourism and Hospitality Research in Ireland Conference (THRIC).

Hussey, J., Holden, M. T., \& Lynch, P. (2011, 19-22 October). A concept of professionalism in tourism. Paper presented at the 29th EUROCHRIE Conference.

Iverson, R. D., \& Deery, M. (1997). Turnover culture in the hospitality industry. Human Resources Management Journal, 7(4), 71-82.

Kalleberg, L. A., \& Stark, D. (1993). Career strategies in capitalism and socialism: Work values and job rewards in the United States and Hungary. Social Forces, 72(1), 181-198.

Kam, C., Morin, A. J. S., Meyer, J., \& Topolnytsky, L. (2016). Are commitment profiles stable and predictable? A latent transition analysis. Journal of Management, 42(6), 14621490.

Karatepe, O. M., \& Shahriari, S. (2014). Job embeddedness as a moderator of the impacts of organisational justice in turnover intention: A study in Iran. International Journal of Tourism Research, 16(1), 22-32.

Kim, N. (2014). Employee turnover intention among newcomers in travel industry. International Journal of Tourism Research, 16(1), 56-64.

Kim, J. S., Song, H. J., \& Lee, C. K. (2016). Effects of corporate social responsibility and internal marketing on organizational commitment and turnover intentions. International Journal of Hospitality Management, 55, 25-32.

Lee, K.-J. (2014). Attitudinal dimensions of professionalism and service quality efficacy of frontline employees in hotels. International Journal of Hospitality Management, 41, 140-148.

MacKenzie, S. H., \& Kerr, J. H. (2013). Stress and emotion at work: An adventure tourism guide's experiences. Tourism Management, 36, 3-14.

Meyer, J. P., \& Allen, N. J. (1997). Commitment in the workplace: Theory, research and application. Sage.

Morrow, P. C. (1993). The theory and measurement of work commitment. JAI Press.

Price, J. L., \& Mueller, C. W. (1981). A causal model of turnover for nurses. The Academy of Management Journal, 24(3), 543-565.

Randall, D. M., \& Cote, J. A. (1991). Interrelationships of work commitment constructs. Work and Occupation, 18(2), 194-211.

Silva, S., \& Martins, D. (2016). Human resource management in hotel units: The Portuguese case. Academica Turistica, 9(1), 5-18.

Sinclair, R. S., Tucker, J. S., \& Cullen, J. C. (2005). Perfor- 
mance difference among four organisational commitment profiles. Journal of Applied Psychology, 9o(6), 12801287.

Vodopivec, N. (2014). Družbene solidarnosti v času socialističnih tovarn in individualizacije družbe. Ars \& Humanitas: Revija za Umetnost in Humanistiko, 8(1), 136-150.
Youn, Lee, K., \& Lee, S. (2018). Effects of corporate social responsibility on employees in the casino industry. Tourism Management, 68, 328-335. 